Perceived Managerial and Leadership Effectiveness in a Korean Context

An Indigenous Qualitative Study

\author{
Dae Seok Chai \\ Texas A\&M University, USA \\ Shinhee Jeong \\ Texas A\&M University, USA \\ Junhee Kim \\ Texas A\&M University, USA \\ Sewon Kim \\ State University of New York (SUNY) Empire State, USA \\ Robert G. Hamlin \\ University of Wolverhampton, UK
}

Doi: 10-1007/s10490-016-9476-x 


\section{Perceived managerial and leadership effectiveness in a Korean context: An indigenous qualitative study}

\section{Introduction}

Multinational corporations (MNCs) across the world have sent an increasing number of managers abroad to leverage unprecedented opportunities in the era of globalization. However, their failure rate has been above $33 \%$ for decades, resulting in substantial costs (Puck, Kittler, \& Wright, 2008). One of the primary reasons for this failure is a lack of understanding of the national and organizational cultures within the host countries (Festing \& Maletzky, 2011). For example, while a number of MNCs have entered the Korean market, several such as Yahoo, Motorola, and Walmart have failed and withdrawn due to the companies' lack of adjustment to the Korean cultural context (Choe, 2006; Woo, 2013).

In spite of the significance of culturally embedded practices, most researchers who have explored management and leadership in Asian countries, whether they were Western or indigenous researchers, have implemented studies using extant Western management and leadership theories derived within the Western cultural context (Leung, 2007; Tsui, 2006). Numerous scholars have claimed that this could be problematic because the findings of such studies may not be applicable to non-Western countries (Li, 2012; Liden \& Antonakis, 2009), and may fail to provide insights and understanding of novel contexts or to reveal indigenous aspects of management and leadership (Tsui, 2007). Consequently, there have been increasing calls for indigenous management and leadership research within Asian countries (see Li et al., 2014; Lyles, 2009; Tsui, 2004; Wolfgramm, Spiller, \& Voyageur, 2014). 
Over the past 30 years, managerial effectiveness and leadership effectiveness have been substantially neglected areas of management research (Noordegraaf \& Stewart, 2000; Yukl, Gordon, \& Taber, 2002). In addition, there has been little agreement on what specific behaviors distinguish effective managers from ineffective ones. Furthermore, more research is needed to examine the managerial and leadership behaviors that are critical for shaping the performance of individuals, groups and organizations (see Borman \& Brush, 1993; Cammock, Nilakant \& Dakin, 1995; Mumford, 2011; Noordegraaf \& Stewart, 2000; Yukl et al., 2002). While most of the research related to managerial and leadership effectiveness has been conducted in the U.S., the few notable non-U.S. studies include that of Cammock et al. (1995) in New Zealand who developed a behavioral lay model of managerial effectiveness using the repertory grid technique. Another notable exception is the cumulative series of perceived managerial and leadership effectiveness studies conducted by Hamlin with various indigenous co-researchers in Western and non-Western countries (see Hamlin \& Patel, 2012; Ruiz, Wang, \& Hamlin, 2013) using Flanagan's (1954) critical incident technique (CIT).

\section{Purpose of the study}

Our study builds upon and extends Hamlin's prior research into Korea. The ultimate aim of the current study was to identify what Korean managers and non-managerial employees perceive to be effective or ineffective managerial behaviors from an emic and subjectivist epistemological perspective. The paper is divided into four sections. First, we review the literature related to the focus and design of our study. Second, we describe the research methodology and methods used. Third, we present our findings which include a derived set of overarching indigenous themes of Korean managerial behavior and descriptions of how Korean cultural concepts are embedded within them. Fourth, we discuss the distinctive significance and 
the theoretical implications of our findings, their implications for practice, the limitations of the study, and several directions for future research.

Before proceeding further it is important to note that we make no rigid distinction between management and leadership because (a) they are not disparate or distinct constructs (Alvesson \& Sveningsson, 2003; Kotterman, 2006) and (b) doing so is not helpful in practice (Middlehurst, 2008). Managing and leading are integral parts of the everyday management task of the manager, and many if not most people within organizations use the terms interchangeably (Raelin, 2004; Yielder \& Codling, 2004). Thus, managerial behavior in this study refers to both manager behavior and leader behavior, and leadership refers to the supervisory leadership (House \& Aditya, 1997) performed by managers at all levels and does not refer to the strategic leadership performed by top managers (House, Hanges, Javidan, Dorfman, \& Gupta, 2004).

\section{Literature Review}

In this section, we review the three areas of literature that have a direct bearing on the focus and design of our study. First, we discuss implicit leadership theory (ILT) and personally held cognitive prototypes that individuals use to perceive and interpret the behavior of others. Second, we discuss the national and corporate cultures of Korea which could impact individuals' cognitive prototypes on managerial effectiveness. Third, we highlight various criticisms of most management and leadership studies in Asian and Korean contexts and calls for advanced types of indigenous research. The section concludes with a statement of the three research questions.

\section{Implicit leadership theory}

Tsui (1990) argued that managers are perceived and judged by multiple constituencies or stakeholders (e.g., superiors, peers, subordinates). According to ILT, these stakeholders have their own beliefs, convictions, and assumptions to encode, process, and recall the specific events, 
attributes, and behaviors (Shaw, 1990) that distinguish good managers from bad managers (Eden \& Leviathan, 1975) and leaders from non-leaders (Shondrick, Dinh, \& Lord, 2010). Such cognitive categorization processes result in managers and non-managerial employees personally holding implicit cognitive prototypes of what they perceive as a behaviorally effective or ineffective manager (Phillips \& Lord, 1986), and they evaluate and judge managers against these cognitive prototypes (Cronshaw \& Lord, 1987; Foti \& Luch, 1992). The better the fit between individuals' personally held cognitive prototypes of what an effective or ineffective manager looks like and what they actually perceive and experience, the more likely it is that they will judge the managers they observe as being either effective or ineffective. Various scholars argue that the cognitive prototypes held by managers and non-managerial employees are sensitive to context (Shondrick \& Lord, 2010), and are likely to be influenced by the corporate culture of their respective organizations (Gerstner \& Day, 1994) and by their native national culture (Helgstrand \& Stuhlmacher, 1999). Consequently, a key aim of this Korean study is to explore the extent to which Korean cultural concepts are semantically and latently embedded in the language and meaning of collected perceptions of effective and ineffective managerial behavior.

\section{Korean cultural concepts}

As Korean culture has been influenced by Chinese culture due to geopolitical reasons, it is strongly rooted in Confucianism (Pratt, 2006). Thus, understanding Confucianism is critical to understanding Korean culture as it was a national ideology and has dominated Korean culture for several centuries (Kim \& Park, 2003). Confucianism could be summarized with four key principles: (a) hierarchy for stability and order, (b) long-term oriented self-cultivation, (c) a harmony with others, and (d) virtuous behaviors for humanness (Chuang, 2012; Lin \& Ho, 2009). Influenced by these Confucian principles, Korean culture emphasizes a humanistic perspective 
and proper relationships as the foundation for society, and stresses group harmony (Lee, 2012), ethical behavior (Ames \& Rosemont, 1998), the virtue of humility (Knutson, 1996), a respect for hierarchy (Merkin, 2009), and in-group loyalty and affection and out-group distrust (Horak, 2014). Due to a long-term perspective (Chen \& Chung, 1994), learning and self-cultivation is also emphasized in Korean culture. Based on these roots, the national culture of modern Korea is often characterized as collectivistic (Cho \& Yoon, 2001), hierarchical (Lee, 2012), paternalistic (Kim, 1994), high context, and concerned with saving face (Merkin, 2009).

In this Confucian cultural context, a Korean private organization has a unique cultural context. For example, chae-bol, a large authoritarian and hierarchical Korean conglomerate (Chang, 2012), is composed of 40 to 60 legally independent companies, controlled by the parent company which is owned by the original founder or the founder's family members (Choi \& Patterson, 2007). Since Korea was historically controlled by an imperial system and a bureaucratic government structure, the authority of a leader (e.g., king, father, and teacher) could not be challenged, and followers needed to be protected by the moral guidance of Confucian values within the established social hierarchy. For example, one of the Confucianism teachings is the trinity of the king, teacher, and father, which means individuals should have an equally high degree of respect for and loving relationships with their leaders in various contexts (Ames \& Rosemont, 1998). Within this relationship, individuals expect the leaders of their country, family, and classroom to take care of them. Therefore, in a Korean corporate cultural context paternalistic leadership styles based on Confucianism have been widely implemented (Chang, 2012). Organizations and leaders require strong discipline and authority while employees expect fatherly benevolence (Farh \& Cheng, 2000).

\section{Indigenous management studies within Asian contexts}


What qualifies as indigenous research is still open to debate because there is no widely accepted definition. According to Lyles (2009) and Li (2012), indigenous research is the study of a unique local phenomenon or a unique element of any local phenomenon from a local (native as emic) perspective that aims to explore/examine its local implications/relevance, and, if possible, its global implications/relevance. However, Tsui (2007: 1353) argued that an indigenous study referred to "any single country study that is context-specific as a result of either incorporating aspects of the national context in the theory and methods," or by researchers “taking the national context as granted." For our emic study, we have adopted Tsui's (2007) definition of indigenous research. According to Harris (1999), the emic perspective refers to the viewpoint of participants or insiders, while the etic perspective is from the viewpoint of observers or outsiders. Furthermore, the emic stance adopted for our study fits closely with the notion that "an emic perspective attempts to capture participants' indigenous meanings of realworld events" (Yin, 2010: 11) and "looks at things through the eyes of members of the culture" where a phenomenon is being studied (Willis, 2007: 100).

To provide clarity regarding the diverse nature of indigenous research, both Lyles (2009) and $\mathrm{Li} \mathrm{(2012)} \mathrm{have} \mathrm{offered} \mathrm{an} \mathrm{integrative} \mathrm{framework} \mathrm{and} \mathrm{a} \mathrm{typology,} \mathrm{respectively.} \mathrm{Both}$ constructs are comprised of four stages of sophistication or advancement, the applicability of which depends on the nature of the local phenomenon to be studied and/or the philosophical/paradigmatic position and etic or emic stance adopted by the researcher. We present below a synthesis of how the four types of indigenous research have been conceptualized by Lyles (2009) and Li (2012).

Stage 1 (emic-as-etic with mostly Western content) 
Stage 1 is the most basic and common approach which involves a naïve/uncritical application of theories from the West in a local context. A vast majority of management and leadership studies carried out in Asian countries, including Korea, have been imposed etic inquiries and belong to this category (Li, 2012). However, as Liden and Antonakis (2009) argued, the findings and interpretations do not always match the management practices in specific national contexts due to the uncritical local application.

Stage 2 (etic-to-emic with an imbalanced Western-Eastern content)

Stage 2 is a more advanced approach involving a cross-cultural comparative component with the potential to discover one or more novel constructs that are unique to the local phenomenon from an etic perspective. Hofstede et al.'s (2010) cultural dimension study and House et al.'s (2004) GLOBE study are examples of Stage 2 research. They described effective Korean managers as authoritarian, achievement oriented, decisive, competent, inspiring, team oriented, self-centered, face saving, and autocratic.

Stage 3 (emic-as-emic with mostly Eastern content)

Stage 3 is an innovative approach exploring local phenomena from an emic perspective involving the identification and development of novel local constructs. Inspiration is identified from local values or classical beliefs, and it builds new local context-specific theories to complement those from a Western perspective. For example, Choi, Yoon, and Jeung (2012) inductively derived two sets of leadership competencies at the executive and manager levels using the Delphi method. Multiple competencies were identified in their findings, such as managing performance, demonstrating enthusiasm for goal achievement, communicating effectively, coaching followers, and building teamwork. Wang's (2011) managerial effectiveness study in China is a specific example of indigenous research within the same 
national cultural roots that has provided insights into the issue of managerial and leadership effectiveness in a Korean context. She identified a set of perceived effective and ineffective managerial behaviors manifested by Chinese managers in a Chinese state-owned for-profit-like enterprise. Her findings supported a paternalistic leadership style that is significantly influenced by Confucianism, and she identified the transformation of Chinese leaders' roles through the influence of Western values.

Stage 4 (emic-and-etic integration with well-balanced local-global or Eastern-Western content)

Stage 4 is the most advanced approach involving an integration of emic theories resulting from Stage 2 and Stage 3 types of indigenous research conducted in different local/cultural contexts. The aim of such studies is to build cross-cultural constructs/theories by transforming emic theories into "a mosaic-style etic core and emic detail" (Li, 2012: 852) and thereby generating geocentric/global context-general knowledge. An example of this type of indigenous research is that of Cheng $(1995,1996)$ who attempted to build an indigenous theory based on Confucianism through a series of emic qualitative studies. Based on Cheng's research, Farh and Cheng (2000) conceptualized paternalistic leadership as having three dimensions, namely authoritarianism, benevolence, and morality. Adopting a Stage 4 (emic-and-etic) approach, various researchers have examined the concept of paternalistic leadership in both Asian and other cultural contexts (e.g., Turkey (Pellegrini \& Scandura, 2006), India, and the U.S. (Pellegrini, Scandura, \& Jayaraman, 2010)). Cheng et al. (2014) particularly identified that effective Korean managers possess morality and are benevolent, but not authoritarian.

Most studies on Korean management and leadership have been conducted from a Stage 1 (emic-as-etic) indigenous research perspective, which led Li (2012) to call for more advanced indigenous studies. In addition, most of the extant studies have focused on exploring the 
preferred leadership styles or competencies of managers rather than the perceived effective/ineffective managerial and leadership behaviors. Considering the dynamics of culture, the incongruence between emic and etic perspectives (Leung, Bhagat, Buchan, Erez, \& Gibson, 2005), and a scarcity of advanced indigenous managerial and leadership effectiveness research, we conducted a Stage 3 (emic-as-emic) indigenous study with three specific research questions:

$R Q 1$. What types of managerial and leadership behaviors do managers and nonmanagerial employees within multiple Korean private sector organizations perceive to be effective or ineffective?

$R Q 2$. Which Korean cultural concepts appear to be present within the empirical findings from $R Q 1$ either at the semantic or latent level?

$R Q 3$. Can the findings from $R Q 1$ and $R Q 2$ be expressed in the form of indigenous Korean themes of perceived managerial and leadership effectiveness?

\section{Research Method}

Our philosophical perspective was informed by pragmatism and a pragmatic approach (Morgan, 2007) which allows researchers to adopt paradigmatic assumptions that best fit the research purpose and questions (Cunliffe, 2011). Consequently, we assumed a post-positivist ontology and constructivist-interpretivist epistemology (Guba \& Lincoln, 1994; Ponterotto, 2005), and adopted a qualitative hermeneutic methodology.

\section{Sampling and selection criteria}

The approach adopted for determining our sample of research participants was influenced by the multiple constituency (MC) model of organizational effectiveness which Tsui (1990) used to explore managerial effectiveness at the human resource sub-unit level. She suggested that managerial effectiveness is the extent to which a manager's behavior is congruent with his or her constituents' judgments of what they perceive to be effective or ineffective within a given context. Satisfaction or dissatisfaction with the managerial behaviors, manifested within an 
organization in terms of how well they are in-fit with the implicit cognitive prototypes held by individual constituency members (e.g., superiors, peers, subordinates), can affect their respective attitudes toward individual managers and how they judge those managers (Shipper \& Davy, 2002). Consequently, we collected our empirical data from a sample of research participants comprised of both managers and non-managerial employees.

Following the logic of purposive and criterion sampling strategies for richness and quality assurance of data (Merriam, 2009), we recruited interview candidates following three criteria. First, interviewees should be Koreans in nationality and cultural background. Second, the organizations they worked for must have a staff of 10,000 or more and be listed in Korea's 100 best companies (KFTC, 2012) because we thought we could obtain richer data. We assumed that employees in large companies have more opportunities to observe various types of managers and executives across more departments compared to employees in small companies. Last, interviewees must have worked in their organizations for more than two years so that they had adequate opportunities to observe their managers. Ultimately, 45 research participants were secured from different levels of the respective companies. Of the 45 participants, 25 were male and 20 were female ranging in age from 26 to 53; 10 were executives, 9 were senior managers, 12 were managers, and 14 were non-managerial employees.

\section{Data collection}

Flanagan's (1954) CIT was used to collect concrete examples from our research participants of observed managerial behaviors that they perceived as effective and ineffective. CIT focuses on participants' actual cases rather than on their opinions, and allows for a broad range of responses to be collected (Gremler, 2004). It is one of the best research techniques for 
exploring the performance aspects of managerial behavior (see Borman \& Brush, 1993; Latham \& Wexley, 1981) and is particularly useful for comparative work (Chell, 2004).

\section{Interview procedures}

We sent an email to everyone on the candidate list asking for their participation, and describing our study, the reasons they were chosen, and the possible risks and benefits. After candidates agreed to participate, phone or virtual interviews were arranged because of the geographical distance between interviewers and interviewees. Prior to the interviews, key terminology was made clear to the participants including critical incident (CI) and effective and ineffective managerial performance. We used the following definitions for the current study based on the CIT protocol devised by Hamlin (1988) for his original study of managerial effectiveness, which he adapted from Latham and Wexley's (1981:49) definitions of effective and ineffective managerial performance. In his study, effective managerial performance was defined as "behavior which you wish all managers would adopt if and when faced with a similar circumstance." Ineffective managerial performance referred to "behavior which, if it occurred repeatedly or was seen once in certain circumstances, might cause you to begin to question or doubt the ability of that particular manager in that instance." To elicit incidents of effective and ineffective managerial behavior from the interviewees, we asked three interview questions:

1. What was the background situation, circumstance, or context that led up to the critical incident you have in mind?

2. What exactly did the manager you observed do/say or not do/say, and/or in what way did s/he do/not do or say/not say that was either effective or ineffective?

3. What was the specific outcome of the critical incident that you have described, and on reflection why do you perceive this to be an example of effective or ineffective managerial behavior? 
Participants were invited to provide four or more CIs of effective and four or more CIs of ineffective managerial behaviors that they had personally observed during the six months immediately prior to the interview. Follow-up and probing questions were asked to ensure that the critical aspect of behavior was well articulated. We emphasized to participants who were themselves managers that they should share their observations of other managers and not offer examples based on their own experiences of being managers. Each interview lasted from one to two hours and was tape-recorded with permission. All interviews were conducted in Korean.

\section{Data analysis: Phase 1}

We conducted the data analysis in two phases. This phase addressed the first research question and was conducted in three steps.

Step 1 (usable incident identification)

In total, 715 single-spaced pages of verbatim transcripts were obtained from the taperecorded interviews, from which 322 CIs for effective behavior and 249 CIs for ineffective behavior were extracted. There were about seven effective and five ineffective CIs from each participant and each CI was composed of one or two sentences with 19 words, on average. These procedures of extracting CIs were cross-checked among the four Korean authors. A member check (Patton, 2002) was conducted to determine whether the CIs from the interview transcripts were identical to what the interviewees shared. For any inaccuracy, the transcript was revisited and revised. Then, the CIs were translated from Korean to English and back-and-forth translated several times until consensus was reached.

\section{Step 2 (concept identification)}

The extracted CIs became the units of analysis, and meaningful elements of data were identified for further analysis. To generate shortened and manageable data (Weber, 1990), each 
CI was subjected to open coding (Flick, 2002) to identify its unit of meaning (concept/code). The coded CIs were then subjected to inductive axial coding (Flick, 2002) applied at the semantic level using a card-sorting technique to search for evidence of sameness, similarity, or an element of congruent meaning. They were grouped accordingly into the maximum number of discrete behavioral categories. For verification, the four native Korean authors jointly conducted these open and axial coding procedures three times, and reconciled any discrepancies through discussion until consensus was reached. Following Ruiz et al. (2013), sameness was deemed to exist when the sentences or phrases used to describe two or more CIs were identical or near identical. For example, several participants had used exactly the same phrase "behaves as a role model," and consequently these CIs were grouped based on their sameness. Similarity was deemed to exist when the CI sentences and/or phrases were different but the basic meaning was the same. As an example, several CIs describing a manager's engagement in self-development, learning, adaption, and/or studying were sorted into one group based on their similarity in meaning regarding aspects of personal development. Congruence existed where there was an element of sameness or similarity in the meaning of certain phrases and/or key words. Each behavioral category was analyzed, interpreted, and labeled with a behavioral statement (BS) describing, in essence, the meaning held in common with all of the constituent CIs. The BSs were derived either by selecting one representative verbatim CI from the group of CIs constituting each category, or creating a compound statement from its constituent CIs. Finally, all five authors reviewed the coding and categorization of the CIs and arrived at a consensus on the derived BSs.

Step 3 (category identification) 
The procedures at this step were similar to those of the second but at a higher level of abstraction. The BSs became the unit of analysis for identifying broader core categories around which they could be grouped and integrated by subjecting them to a further round of content analysis using selective coding (Flick, 2002) to identify broad behavioral categories (BCs). All five authors were engaged in the verification processes that were similar to those adopted at Step 2 which included several trials of sorting, resorting, and reconciliation.

\section{Data analysis: Phase 2}

To address the second and third research questions, the four native Korean authors examined the BCs and BSs derived by the Phase 1 data analysis through the lens of the native Korean authors' collective understanding of Korean cultural concepts. This was conducted at both the semantic and latent levels of analysis and also included an examination of the respective underpinning CIs. At the latent level, the authors used thematic analysis (Braun \& Clarke, 2006; Flick, 2002) as a means of identifying overarching indigenous themes of Korean managerial behavior by surfacing the underlying ideas, values, and assumptions of Korean national and corporate culture embedded within the data. The derived themes were then used as coding categories for categorizing the BCs so as to demonstrate which Korean cultural concepts were explicitly or implicitly embedded within them. Finally, all five authors reviewed the coding and categorization of the BCs and arrived at a consensus on the derived overarching themes.

\section{Ensuring the trustworthiness of the findings}

Forms of triangulation were implemented to enhance the credibility and dependability of the findings. The authors who collected our CIT data engaged in a member checking procedure (Patton, 2002); this was to ensure the CIs the authors had obtained reflected accurately the intended meaning conveyed by their respective CIT informants. Investigator triangulation 
(Merriam, 2009) was used for each of the three steps of data analysis. Initially the respective analyses of the derived CI data sets and the derived BS data set were conducted independently and then jointly by the authors. The authors then respectively engaged in a process of code cross-checking (Gibbs, 2007) to verify and arrive at a mutual confirmation of where the authors' individual interpretations converged and diverged (Knafl \& Breitmayer, 1991). When there were disagreements, they were resolved through discussion until a consensus was reached.

\section{Findings}

In response to the first research question, we first present the results of the CIT data collection and analysis by listing the derived BCs. Regarding the second and third research questions, we respond by providing descriptions of the identified overarching indigenous themes of Korean managerial behavior and of how Korean cultural concepts are embedded within them.

\section{Effective/ineffective leadership behaviors in the Korean cultural context}

A total of 53 effective and 51 ineffective BSs were derived from the 322 effective and 249 ineffective CIs collected from the 45 participants. Each BS was derived from 2 to 13 CIs (mean $\mathrm{n}=5.49$ ). Ultimately, this resulted in the emergence of 20 positive (effective) and 18 negative (ineffective) BCs. Figure 1 illustrates the data analysis process of how a positive or negative $\mathrm{BC}$ was generated from the respective BSs and CIs underpinning them, which represents the phase 1 analysis. Including the phase 2 data analysis process, Figure 1 also presents the overall data structure. The lists of derived positive and negative BCs are shown in Table 1. The lists of positive and negative BCs provide a rich description of what behaviorally distinguishes effective from ineffective managers, which were perceived by Korean managers' superiors, peers, and subordinates. In Table 1 , there are the italicized $P$ and $N$ numbers set in brackets at the end of the descriptions of 6 of the 20 positive $\mathrm{BCs}(P: 2,5,11,12,14, \& 20)$ and 
6 of the 18 negative $\mathrm{BCs}(N: 4,5,11,12,15, \& 16)$. These particular BCs are near polar opposite in meaning whereby a negative $\mathrm{BC}$ describes an absence of the corresponding positive BC type of managerial behavior. Consequently, each pair of these dichotomous BCs could be regarded as belonging to a single behavioral construct, thus leaving 32 discrete BCs. 


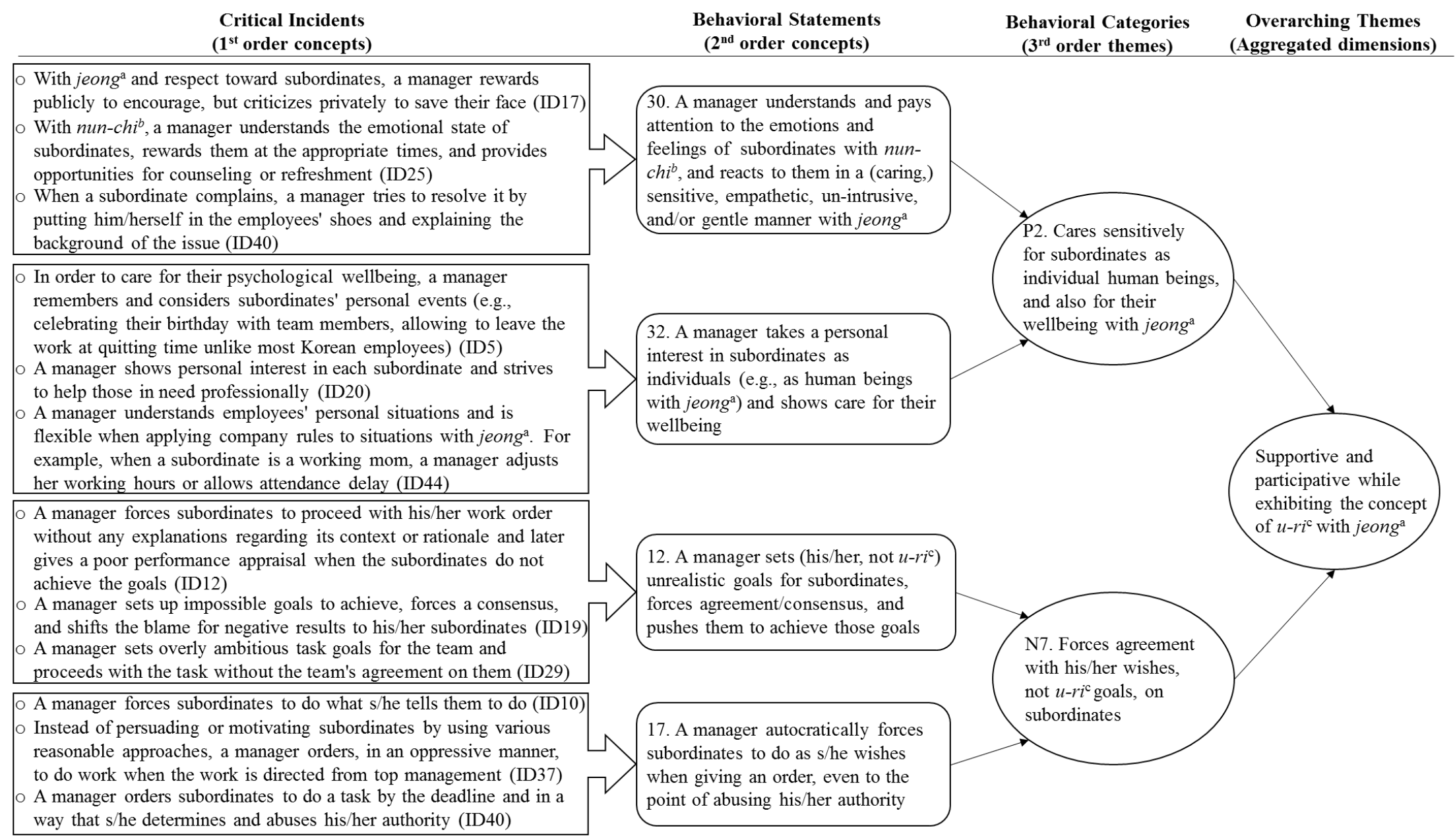

Figure 1 Data analysis process from CIs to BSs to BCs to an overarching theme that represents the data structure

Note. Definitions of indigenous terms are provided below.

a. "An unconsciously formed psychological bond with somebody or something through contacts over time" (Yang \& Kelly, 2009: 302-303)

b. The ability to reading others' mind and being perceptive and thoughtful (Robinson, 1996)

c. As the basis of group social capital, u-ri means in-group, and the set of resources are available to a group through group members' social relationships within the group's social structure (Oh, Chung, \& Labianca, 2004) 
Table 1 Derived positive and negative BCs

\section{Positive BCs}

P1. Protects subordinates while taking or sharing the responsibility, and avoiding finding fault or blaming subordinates for team/employee mistakes

P2. Sensitively cares for subordinates as individual human beings, and also for their well-being with jeong $^{a}($ N12)

P3. Mediates for, stands up for, and/or acts as a shield for his/her department, team and/or subordinates

P4. Gives clear explanation of task goal expectations and how these are to be achieved

P5. Allocates/assigns work and tasks fairly and clearly, and commensurate with a subordinate's abilities (N4)

P6. Envisions the future, establishes goals in line with strategic plans, and/or shares them with subordinates

P7. Aligns work and personal goals of teams and subordinates with the organization's goals

P8. Behaves as a role-model/Leads by example

P9. Provides positive reinforcement using praise, recognition, reward, and/or encouragement

P10. Promotes and facilitates subordinates' personal development and a learning environment

P11. Provides helpful and timely feedback on employee behavior, performance, and mistakes (N16)

P12. Builds camaraderie and trusting relationships like a family (N15)

P13. Creates/fosters a positive working environment and good interpersonal relationships within and between teams (e.g., participative team meetings and a collaborative culture)

P14. Involves employees in decision making (N5)

P15. Actively listens to subordinates' ideas, opinions and/or concerns, and shares company information that may affect them

P16. Adopts a flexible approach and gives customized feedback

P17. Produces plans and makes decisions efficiently and effectively based on his/her expertise and/or nun-chi ${ }^{b}$

P18. Simplifies and standardizes work processes based on his/her expertise and/or experience

P19. Shows trust in subordinates' capabilities, and actively empowers/delegates authority and responsibility to them

P20. Appraises individual performance and provides feedback, based on objective criteria (N11)

\section{Negative BCs}

N1. Sets unrealistic and/or short term goals unaligned with organizational goals

N2. Manages in an unorganized or inconsistent way

N3. Gives instructions and directions without properly understanding orders from above or potential difficulties for subordinates, and/or assigns tasks without a clear explanation

N4. Allocates tasks and responsibilities in an uneven, confusing, or burdensome way, due to his/her lack of expertise, experience, and/or $n u n-\operatorname{chi}^{b}(P 5)$

N5. When making decisions, fails to consult with or actively listen to the opinions and suggestions of employees/team members (P14)

N6. Applies rigidly/inflexibly established rules and/or methods regardless of exceptional circumstances or suggestions for change made by subordinates

N7. Forces agreement with his/her wishes, not $u$ - $r i^{c}$ goals, on subordinates

N8. Looks after own interests at the expense of subordinates

N9. Manipulates and/or misuses resources, processes, and/or subordinates for own self-interest or che-myun $^{d}$

N10. Shows favoritism, based on his/her yeon-go $o^{e}, k i-b u n^{f}$, and/or preferences, and other forms of discrimination

N11. Evaluates and judges subordinates unfairly and/or unjustly $(P 20)$ 
N12. Shows lack of consideration, jeong ${ }^{a}$, and/or sensitivity for subordinates as individuals, and/or for their work life balance or well-being, due to an extreme collectivist approach $(P 2)$

N13. Delays/procrastinates in making decisions, evades responsibilities, and/or avoids taking action due to his/her che-myun ${ }^{d}$ or lack of expertise

N14. Criticizes subordinates in public, and/or reprimands them in ways that offends, insults, demeans, or humiliates them

N15. Shows no trust in his/her subordinates' capabilities and does not empower them (P12)

N16. Omits to monitor his/her subordinates' progress and performance, and/or to provide feedback/guidance to improve (P11)

N17. Deprives subordinates of advice/help, makes no direct contact with them, and/or shows no interest in their or his/her own training and development

N18. Allows own personal emotions and/or the influence of alcohol to affect the way he/she interacts with employees and solves problems

Note.

i. $\quad \mathrm{P}=$ positive $\mathrm{BC} ; \mathrm{N}=$ negative $\mathrm{BC}$.

ii. The italicized $\mathrm{P}$ and $\mathrm{N}$ numbers indicate those $\mathrm{BCs}$ that are near polar opposite in meaning.

iii. Definitions of indigenous terms are provided below.

$\mathrm{a}, \mathrm{b}$, and $\mathrm{c}$ are defined in Figure 1

d. The concept of self and inter-relational concerns with others (Shim, Kim, \& Martin, 2008)

e. The informal relation-based ties between people that stem from school (hak-yeon), regional (jiyeon), or kin (hyul-yeon) origin (Horak, 2014)

f. A combination of mood, feeling, and emotions (Kim, 2002)

We regard these $\mathrm{BCs}$ as generic behavioral criteria of perceived managerial and leadership

effectiveness relevant to and transferable across the Korean private sector.

\section{Overarching indigenous themes of Korean managerial behavior}

As a result of the Phase 2 data analysis, seven overarching indigenous themes of Korean managerial behavior were identified. Next, we discuss these emergent themes in greater detail.

a) Supportive and participative managers who exhibit the concept of $u$-ri with jeong are considered effective in Korea. The term $u$-ri originated from a concept of home which refers to the notion of we within the context of in-groups. As the basis of group social capital, the set of resources are available to the in-group through group members' social relationships within the group's social structure (Oh et al., 2004). Jeong refers to "an unconsciously formed psychological bond with somebody or something through contacts over time" (Yang \& Kelly, 2009: 302-303). Jeong is particularly characterized by sympathy and concern for others and is promoted by paternalism and favoritism (Lee, 2000). Since an individual is considered 
imperfect and partial in Confucianism, mutual dependence in a group is necessary with the assumption of interdependent self (Markus \& Kitayama, 1991). Once the boundary of $u$-ri is formed, group members feel a sense of intimacy, care personally, share information, and show and require solidarity and loyalty. As members of $u$-ri share their jeong through interactions, the concept of $u$-ri becomes stronger (Yang \& Kelly, 2009). In contrast, if the boundary of $u$-ri is broken, group members possibly possess out-group distrust (Horak, 2014).

In our study, being supportive and participative could be categorized into two parts: work- and non-work-related contexts. In both contexts, our participants preferred that managers treat their subordinates as a family or an in-group member within $u$-ri. Exemplary behaviors of being supportive and participative within work-related contexts include providing constructive and thoughtful feedback; sharing information; empowering; and encouraging, rewarding and recognizing subordinates. One of the exemplary incidents is as follows:

My manager shares high quality and key information about our organization within our team so that we can be aware of the overall context and situation for tasks and prepare in advance. (ID43)

In this CI, the manager formed the boundary of $u$-ri and shared valuable information with the ingroup members. As the team members perceived that they were taken care of, they considered their manager to be effective. However, once managers broke the boundary by becoming selfish, participants considered them to be ineffective.

In non-work-related contexts, being supportive with jeong is also critical. Jeong is deeply perceived by employees when managers, like fathers, personally care about and treat employees as individual human beings. On the other hand, managers who required an excessive level of solidarity and collectivism while they emphasized jeong among team members were considered to be ineffective. One participant shared her case: 
My previous boss was so extremely collectivistic that he expected us to do everything together. He almost always required us to work overtime together, even though I did not have anything to do, not to leave until everyone finished their overtime work, and not to leave the office before he left. For these requests, he emphasized jeong, but this is too much and doesn't make sense. (ID32)

Confucius encouraged leaders to respectfully listen to other perspectives (Shim et al., 2008). Since managers are also imperfect and incomplete individuals who are interdependent in the concept of $u$-ri, managers in Korea may encourage subordinates' participation to make better decisions from a Confucian perspective. In her Chinese study, Wang (2011) concluded that effective Chinese leaders implement participative leadership styles due to the influence from Western values. Given the cultural similarities between China and Korea, a supportive and participative management style could have also been present in a Korean context, but promoted by Western values.

b) Being fair and just within the concept of $u$-ri is another characteristic of managerial behavior in a Korean context. Confucius emphasized ethics, which is divided into two parts: an ethical character and ethical behavior (Ames \& Rosemont, 1998). According to Lin and Ho (2009), an ethical character is a much broader concept than ethical behavior required by Confucius and is similar to an ethical culture, including benevolence, righteousness, decorum and loyalty. In this ethical culture, Confucius suggested that leaders should be sincere by cultivating moral character and should lead by moral example, so others follow them out of respect (Clark, 2000).

In our study, ineffective managerial behaviors included not only being unfair and unjust and having counterproductive work behaviors, such as making decisions based on their mood swings or feeling and emotion changes (ki-bun; Kim, 2002), but also behaviors that went against the concept of $u$-ri. One participant described her relationship with her manager: 
I have no connection with my boss regarding hak-yeon, ji-yeon, and hyul-yeon. I am just one of the team members. One of my subordinates is from the same hometown as my boss and graduated from the same university. I found out several times that my boss shared critical information only with that subordinate. Also, my boss often assigned critical tasks to him and took him to important social meetings. (ID14)

In this CI, the manager broke the boundary of $u$-ri and unfairly favored a certain employee based on the informal relation-based social ties between people (yeon-go) that stem from a school relationship (hak-yeon), regionalism (ji-yeon), and kinship (hyul-yeon). Since this manager treated team members unfairly and his behavior was not aligned with fatherly benevolence (Farh \& Cheng, 2000), the manager violated both the expected ethical character and ethical behavior (Ames \& Rosemont, 1998), which led the participant to consider the manager ineffective.

c) Being responsible with che-myun could be divided into two perspectives: responsible for tasks and individual words/actions. One perspective is for managers to be responsible for their managerial tasks. This perspective is especially critical as it relates to ineffective Korean managerial behavior. Managers who act irresponsibly are considered ineffective because they make both themselves and their teams lose face or che-myun. The concept of face generally refers to a person's sense of self-respect or level of self-worth (Chang \& Holt, 1994), but the Korean concept of che-myun refers to the concept of self and inter-relational concerns with others (Shim et al., 2008). Since how they are seen by others is significant, Koreans must maintain their own and their in-group's che-myun (Shim et al., 2008). In our study, the CIs of managerial irresponsibility for tasks were deemed to have made the managers and their teams lose che-myun. The consequential collective shame (Lee, 1998) made these exhibited managerial behaviors appear ineffective.

Another perspective of this behavioral theme is for managers to be responsible with chemyun for their own words and actions. A manager in a Korean context needs to be a role model for subordinates to follow (Clark, 2000). For example, one of the most outstanding and 
exceptional scholars in Korean history, Yul Gok Lee, strongly emphasized that leaders should take the initiative and set an example for followers. According to the Great Learning (dae-hak), the strength and peace of a nation comes from governing a country and ruling a family, which could be achieved by disciplining oneself (Gardner, 2007). By cultivating themselves and being role models, managers could be responsible for their words and actions and maintain their chemyun. In our study, effective managers were responsible for their own words and behaviors, and disciplined themselves to become role models. One participant described this behavior:

My manager constantly engages in self-reflection and strives to learn in spite of his busy schedule. Therefore, he quickly adapts to the dynamic business environment and new demands of our organization. (ID2)

d) Being knowledgeable is perceived as critical in a Korean context. In our study, being knowledgeable is categorized into two perspectives. In Confucianism, a powerful person should be a guru who transfers knowledge and personal wisdom (Hofstede et al., 2010); thus, effective Korean managers needed to be knowledgeable. When understanding their business fields and trends, managers should provide insights, recognize the work processes of subordinates, assign tasks fairly and efficiently, and anticipate obstacles. One participant described his manager:

Since my manager went through what I have, he knows pretty much everything, including my routines and specific obstacles. He has been in marketing for more than 10 years and obtained a master's degree. As I have been here only about two years, I know only my part. What I like about him most is that he shares the trends and possible obstacles when he assigns tasks. He also knows my workload, so I do not have to explain what I have done. (ID14)

Another perspective of being knowledgeable is to understand a context through nun-chi. One of the meanings of nun-chi is to read a person's mind and identify the speaker's hidden agenda (Robinson, 1996). Korean culture is considered one of the highest context cultures (Hall, 1976; Merkin, 2009). In this high context culture, individuals should actively listen, identify the speaker's hidden agenda, and react properly given the context (Shim et al., 2008). Although 
every culture has a type of nun-chi, in a Korean context this means putting oneself into the context of the situation and relevant individuals (Shim et al., 2008). Managers with nun-chi understand their organizations' situations and the unspoken agendas and thoughts of upper-level managers and give clear directions to their subordinates.

e) Regarding the theme of long-term orientation, many participants emphasized the need for learning opportunities. In Confucianism, learning is a life-long process rather than just acquiring new knowledge or skills through formal education (Granrose, 2001), which is similar to the current concept of lifelong learning (Su, 2011). Interestingly, knowledge in Chinese characters (知識) literally means learning and questioning (Tang, 2012). Likewise, the concept of learning in Confucianism is a repetitive and never-ending process of learning, reflecting, and questioning (Chuang, 2012). In this sense, opportunities to acquire knowledge and skills are considered long-term rewards in Confucian societies including Korea (Hofstede et al., 2010). In our study, when given learning opportunities, participants perceived that their long-term growth and career development were considered by their managers and they were fully taken care of, as their father would care for them within the boundary of $u$-ri, not just as a leader or colleague would care for them. Participants also considered a manager effective when the manager promotes a learning culture within his/her team. One participant described her manager:

My manager constantly encourages us (team members) to study and learn, and provides available resources so that we can develop our potential and competencies for our continuous growth. (ID37)

The participants also considered assigning challenging tasks or empowering employees to improve their level of competency as effective managerial behaviors. In contrast, participants considered managers to be ineffective when they micromanaged with a sole focus on short-term output or when managers did not have a vision or long-term goal for their teams. 
f) Another overarching theme of Korean managerial behavior is harmonizing in and across teams using in-hwa. A foundation of Confucianism is hierarchy which emphasizes proper relationships in which group harmony must be maintained and can be stabilized by mutual respect and love (in-hwa; Kim, Lee, \& Lee, 2013). An individual group member is expected to implement in-hwa to overcome his/her individuality, respect the other members, and maintain others' che-myun for group harmony (Hofstede \& Bond, 1988; Yang \& Kelly, 2009).

In our study, participants reported that group harmony is required within a team and across teams in order to work together in an organization. While a manager develops and maintains group harmony, nun-chi plays a significant role in allowing the manager to understand the implicit cognitive prototypes of effective and ineffective managers, indicating when, what, and how to behave and speak properly. In several CIs, managers were considered effective when they develop a harmonious and cooperative context while understanding a context with nun-chi, implementing in-hwa, and saving the che-myun of team members. However, an excessive emphasis on harmony without those requirements (in-hwa, nun-chi, and che-myun) caused managers to be considered ineffective. One participant described an overemphasis on harmony:

My team leader excessively emphasized harmony and always wanted us to follow him without question. However, he emphasized harmony his way. Without caring, respect, and trust, our team members were not willing to cooperate. He often treated us like robots. Whenever we complained, he invited us to a drinking party, listened to what we said, and advised us to improve our collaborative spirit. He never solved the issue, but seemed to believe he did. (ID17)

In this CI, an excessive emphasis on harmony and improper use of in- $h w a$ were violations of an ethical character and ethical behavior (Ames \& Rosemont, 1998). The participants in our study often desired individualism, which may break group harmony. They wanted to work independently, be fairly appraised for their individual performance, and have managers respect their privacy. 
g) Finally, managers in a Korean context should be flexible and confident with managing paradox and complexity through zhung-yong (zhong-yong in Chinese), which refers to being reasonable and moderate and avoiding extremeness. Zhung-yong is one of the central aspects of Confucianism with the core principle of maintaining balance, flexibility, and dynamism (Park, 2013). The doctrine of zhung-yong emphasizes a balanced and dynamic mental status that continues to change and be flexible according to a situated time and space, harmonizing between two extremes (Lee, 2006).

In our study, the last indigenous theme was divided into two concepts: being flexible and managing paradox and complexity. First, several participants emphasized the ability to manage flexibly depending on their subordinates' capabilities. Effective managers assigned different types and levels of tasks, delegated tailored responsibilities, and provided feedback according to subordinates' characteristics (e.g., strengths and weaknesses, experience, and/or level of expertise). Effective managers also transformed their managerial style accordingly. Compared to Western HR management that primarily emphasizes job descriptions (Siddique, 2004), this type of flexible management, based on zhung-yong, could be considered an indigenous Korean management style because roles and responsibilities are flexibly assigned according to employees' situations.

More importantly, effective managers in Korea should be confident with managing paradox and complexity through zhung-yong. According to Shim et al. (2008), zhung-yong is a key to managing paradox and complexity in the Korean context. For example, managers should provide firm instructions but in a participative manner; they should care about team members personally but fairly; they should empower but be responsible; they should pursue harmony but embrace differences; and they should make profits but be long-term oriented. Instead of 
choosing one or the other, an effective manager in a Korean context should embrace these different and paradoxical characteristics. One participant described her ineffective manager:

Our team is like a family and my manager always emphasizes a family-like relationship among team members. We work from 8:30 in the morning to 9:00 p.m. or often 11:00 p.m., so we spend most of our day with our colleagues rather than our real families. Yes, my team members are like my family, but because of this 'family relationship,' I cannot take care of my real family. (ID8)

As a summary of our findings, Figure 2 presents a list of the seven overarching indigenous themes of Korean managerial behaviors and which BCs are semantically and latently matched with each of the seven themes. On the upper part of the figure, the positive BCs for each overarching theme are clustered, and the negative BCs are presented on the lower part. BCs driven by the latent analysis are presented in grey. In addition, Table 2 provides the data structure and additional exemplary BCs, BSs, and CIs of each overarching theme.

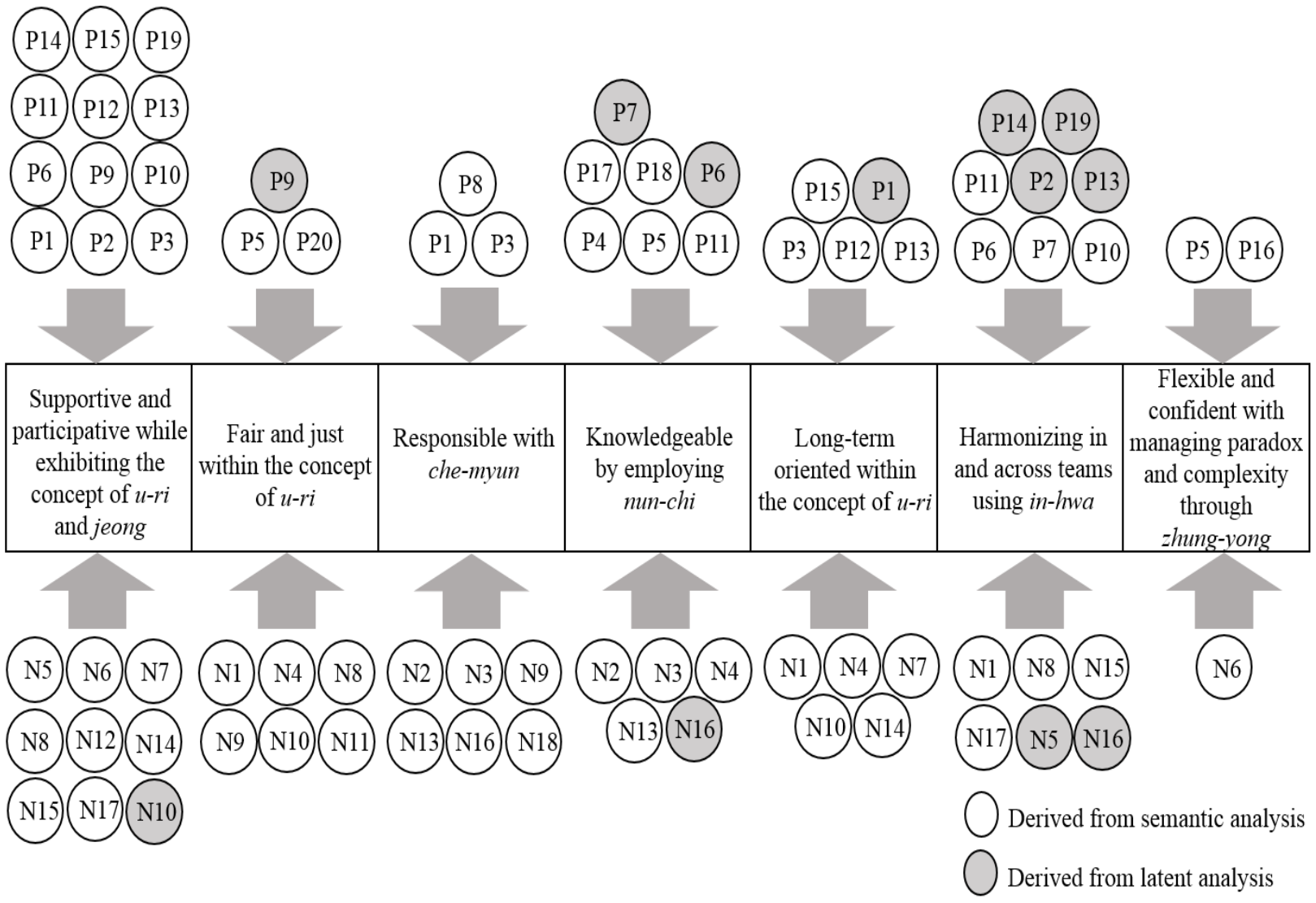

Figure 2 Derived overarching indigenous themes of Korean managerial behavior Note. $\mathrm{P}=$ positive $\mathrm{BC} ; \mathrm{N}=$ negative $\mathrm{BC}$. All indigenous terms are defined in Table 1 and Figure 1 . 
Table 2 Seven overarching themes and additional exemplary BCs, BSs, and CIs

\begin{tabular}{|c|c|c|c|}
\hline Overarching theme & $\mathrm{BCs}$ & BSs & CIs (illustrative quotes) \\
\hline $\begin{array}{l}\text { Supportive and } \\
\text { participative while } \\
\text { exhibiting the concept } \\
\text { of } u \text {-ri and jeong }\end{array}$ & $\begin{array}{l}\text { P2. Sensitively cares for } \\
\text { subordinates as } \\
\text { individual human } \\
\text { beings, and also for their } \\
\text { well-being with jeong }\end{array}$ & $\begin{array}{l}\text { (32) A manager takes a } \\
\text { personal interest in his/her } \\
\text { subordinates as individuals } \\
\text { and shows care for their } \\
\text { wellbeing }\end{array}$ & $\begin{array}{l}\text { "One of my colleagues seriously thought of quitting his job } \\
\text { because his pet died! It sounds silly, but problems and issues } \\
\text { related to people's personal lives affect their professional lives. } \\
\text { Since my manager was aware of it, he took an interest in personal } \\
\text { problems of } u \text {-ri team members. He was willing to play a role as } \\
\text { a father, a brother, or even a friend. He also listened to our } \\
\text { problems with sympathy and took care of our feelings and } \\
\text { psychological wellbeing." (ID26) }\end{array}$ \\
\hline $\begin{array}{l}\text { Fair and just within } \\
\text { the concept of } u-r i\end{array}$ & $\begin{array}{l}\text { P20. Appraises } \\
\text { individual performance } \\
\text { and provides feedback, } \\
\text { based on objective } \\
\text { criteria }\end{array}$ & $\begin{array}{l}\text { (10) A manager sets norms, } \\
\text { standards and criteria against } \\
\text { which to assess the } \\
\text { performance and behavior of } \\
\text { his/her employees, and } \\
\text { rewards or punishes them } \\
\text { accordingly }\end{array}$ & $\begin{array}{l}\text { "My manager uses a } 360 \text { degree feedback system for } \\
\text { performance appraisal. He evaluates each of } u \text {-ri team members } \\
\text { based on a clear and objective job description. Once the } \\
\text { evaluation is done, he gives individual reports and consults with } \\
\text { each of us on our accomplishments, strengths, weaknesses, and } \\
\text { what needs to be improved." (ID8) }\end{array}$ \\
\hline $\begin{array}{l}\text { Responsible with } \\
\text { che-myun }\end{array}$ & $\begin{array}{l}\text { P3. Mediates for, stands } \\
\text { up for, and/or acts as a } \\
\text { shield for his/her } \\
\text { department, team and/or } \\
\text { subordinates }\end{array}$ & $\begin{array}{l}\text { (19) When his/her team as a } \\
\text { whole makes a mistake or has } \\
\text { a problem with other teams } \\
\text { he/she takes responsibility for } \\
\text { it }\end{array}$ & $\begin{array}{l}\text { "My job was to handle all of the money transfers in my company. } \\
\text { One day, one of my partners claimed that our company owed } \\
\text { them money. I consulted with the internal legal team and } \\
\text { concluded that it was true. So, I transferred the money. Later, the } \\
\text { audit team questioned my decision, but I couldn't prove the } \\
\text { process because I didn't document my work process. I made a } \\
\text { mistake and was ashamed. But my manager stood up for me and } \\
\text { explained the situation to the audit team. He took responsibility } \\
\text { for my mistake as he would do for his own mistake. He defended } \\
\text { me, and then I was able to get out of trouble." (ID44) }\end{array}$ \\
\hline $\begin{array}{l}\text { Knowledgeable } \\
\text { by employing nun-chi }\end{array}$ & $\begin{array}{l}\text { P18. Simplifies and } \\
\text { standardizes work } \\
\text { processes based on } \\
\text { his/her expertise and/or } \\
\text { experience }\end{array}$ & $\begin{array}{l}\text { (2) A manager } \\
\text { systematizes/standardizes } \\
\text { task/work routines/processes } \\
\text { and/or creates work manuals }\end{array}$ & $\begin{array}{l}\text { "My manager is experienced and has expertise in most tasks of } \\
\text { our team. Based on his extensive experience, my manager } \\
\text { developed a standardized work process and manual, which helped } \\
\text { our team members work effectively and efficiently. Although I } \\
\text { am the kind of person who is afraid of a new and unfamiliar } \\
\text { project, I feel confident and know what to do next and who to ask } \\
\text { for help with such systemized work processes and manuals." } \\
\text { (ID26) }\end{array}$ \\
\hline
\end{tabular}




\begin{tabular}{|c|c|c|c|}
\hline Overarching theme & $\mathrm{BCs}$ & BSs & CIs (illustrative quotes) \\
\hline $\begin{array}{l}\text { Long-term oriented } \\
\text { within the concept of } \\
u-r i\end{array}$ & $\begin{array}{l}\text { P13. Creates/fosters a } \\
\text { positive working } \\
\text { environment and good } \\
\text { interpersonal } \\
\text { relationships within and } \\
\text { between teams (e.g., } \\
\text { participative team } \\
\text { meetings and a } \\
\text { collaborative culture) }\end{array}$ & $\begin{array}{l}\text { (39) A manager gives } \\
\text { subordinates challenging } \\
\text { tasks/assignments/projects } \\
\text { and/or new opportunities to } \\
\text { motivate and/or improve their } \\
\text { competence/performance } \\
\text { and/or to develop their } \\
\text { personal growth }\end{array}$ & $\begin{array}{l}\text { "My manager tried to develop u-ri team members' competencies } \\
\text { and to strategically promote a learning environment for the long } \\
\text { term. He gave all of } u \text {-ri team members challenging assignments } \\
\text { throughout two years. Those assignments were not directly } \\
\text { related to our actual and current work projects, but he assured us } \\
\text { that the assignments would help us improve and grow. He also } \\
\text { initiated a study group and asked us to analyze and summarize } \\
\text { our jobs/tasks and to suggest what types of changes were needed } \\
\text { to make our jobs/tasks better support the organizational goals. I } \\
\text { didn't like it at first, but in the end, it was definitely a great } \\
\text { opportunity to learn and enhance my competencies." (ID27) }\end{array}$ \\
\hline $\begin{array}{l}\text { Harmonizing in and } \\
\text { across teams using } \\
\text { in-hwa }\end{array}$ & $\begin{array}{l}\text { P7. Aligns work and } \\
\text { personal goals of teams } \\
\text { and subordinates with } \\
\text { the organization's goals }\end{array}$ & $\begin{array}{l}\text { (43) A manager helps } \\
\text { subordinates align their } \\
\text { personal } \\
\text { growth/development/career } \\
\text { goals with the organization's } \\
\text { goals }\end{array}$ & $\begin{array}{l}\text { "When my manager first came to our team, she asserted that our } \\
\text { team could not be successful if there was no strong alignment } \\
\text { between our personal goals and organizational goals. I was } \\
\text { passionate about it and agreed with her because we do not come } \\
\text { to work just for money, but to grow and make a contribution to } \\
\text { where we belong. She tried to help us feel valued in the } \\
\text { organization and explained the contribution each of us made to } \\
\text { the organization. She also encouraged us to plan and pursue our } \\
\text { personal careers in the organization. Our team really began to } \\
\text { give our hearts and souls to achieve the organizational goals." } \\
\text { (ID7) }\end{array}$ \\
\hline $\begin{array}{l}\text { Flexible and confident } \\
\text { with managing } \\
\text { paradox and } \\
\text { complexity through } \\
\text { zhung-yong }\end{array}$ & $\begin{array}{l}\text { P16. Adopts a flexible } \\
\text { approach and gives } \\
\text { customized feedback }\end{array}$ & $\begin{array}{l}\text { (53) A manager flexibly } \\
\text { adopts different } \\
\text { management/leadership styles } \\
\text { depending on the task } \\
\text { characteristics and/or the } \\
\text { competency and styles of the } \\
\text { particular subordinate(s) }\end{array}$ & $\begin{array}{l}\text { "I intentionally shut down and stop working when I am pushed } \\
\text { and criticized by a manager, but I become more productive when } \\
\text { I receive praise. My manager soon discerned my character and } \\
\text { transformed his leadership style for me. For each of the four } \\
\text { members of our team, he used four different approaches } \\
\text { depending on the characteristics of each member. He didn't treat } \\
\text { everyone with one rigid leadership style." (ID10) }\end{array}$ \\
\hline
\end{tabular}

Note. All indigenous terms are defined in Table 1 and Figure 1. 


\section{Discussion}

This article began by discussing the scarcity of both Stage 3 (emic-as-emic) indigenous Korean managerial and leadership studies and managerial and leadership effectiveness research within Asian countries. Our study addressed these gaps by providing rich descriptions of perceived effective/ineffective managerial and leadership behaviors within Korean private companies. We identified 38 broad behavioral categories (BCs) of effective and ineffective managerial behavior derived from the lived experiences and perceptions of and definitions offered by managers and non-managerial employees. Of them, 6 of the 20 positive BCs were polar opposite in meaning to 6 of the 18 negative BCs. This led to the identification of 32 discrete $\mathrm{BCs}$ that could be regarded as the generic behavioral criteria of perceived managerial and leadership effectiveness that are relevant to the Korean context. We also identified several Korean cultural concepts that appear to have influenced the implicit cognitive prototypes of effective and ineffective managers held by our research participants, as presented in Figure 2. No compatible study has been conducted in Korea, and consequently we believe our findings offer a unique contribution to theory and practice, as we discuss in the following section.

\section{Theoretical implications}

Our study has generated new insights and a better understanding of what behaviorally distinguishes effective and ineffective managers within the Korean private sector. Our emergent lists of positive and negative BCs are distinctive, having been derived from lay definitions of perceived managerial and leadership effectiveness offered by people directly involved with Korean managers, namely the managers' superiors, peers and subordinates. Furthermore, the indigenous Korean themes that have emerged from our study offer an insightful, contextually relevant, and richly described understanding of perceived managerial and leadership 
effectiveness within Korean private companies from an Asian philosophical perspective. As we have been unable to find any equivalent Korean study in mainstream Western or non-Western management academic journals, we believe that our inquiry is the first to explore from an emic perspective the perceived effectiveness of managerial behaviors manifested within Korean organizations in private, public, or third (not-for-profit) sectors.

Another distinctive feature of our study is the emphasis given to both effective and ineffective managerial behaviors, and the near equal balance of the two sides with a holistic approach. This is in contrast to most other studies on managerial effectiveness and leadership effectiveness which have focused predominantly on the effective characteristics and behaviors of managers, with the ineffective behaviors receiving far less attention (Padilla, Hogan, \& Kaiser, 2007). Other than Wang's (2011) study in China, the only contemporary managerial behavior research similar and comparable to our emic study is that of Cammock et al. (1995) in New Zealand. However, these latter researchers collected data that included descriptions of managerial characteristics such as intelligence, knowledge, values, temperament, character and personality, as well as of managerial behaviors; but only $12.94 \%(n=22)$ of these behaviors described managerial ineffectiveness. In general, barriers are less frequently studied than enablers for a certain behavior in management studies (Johns, 2006) though barriers are more likely to be critical for understanding employee behaviors in organizations (Stewart \& Nandkeolyar, 2007). In particular, we consider our two-sided approach to be important because, as Amabile et al. (2004) claimed, ineffective behaviors might be more important than effective behaviors in influencing subordinate performance and perceptions of managerial support, and the possible affective reactions to negative behaviors may be stronger than to positive behaviors.

Korean cultural concepts embedded in the overarching indigenous themes 
According to ILT, organizational or national culture plays a pivotal role in shaping an individual's perception of effective/ineffective leadership prototypes, influencing how individuals around leaders evaluate leadership effectiveness and distinguish leaders from nonleaders (Shondrick et al., 2010) within their cultural context (Helgstrand \& Stuhlmacher, 1999; Shondrick \& Lord, 2010). From the overarching indigenous themes of Korean managerial behavior in our findings, we identified Confucianism as a major cultural concept/philosophy that had a profound impact on the leadership prototypes: (a) supportive and participative while exhibiting the concept of $u$-ri and jeong, (b) fair and just within the concept of $u$-ri, (c) responsible with che-myun, (d) knowledgeable by employing nun-chi, (e) long-term oriented within the concept of $u$-ri, (f) harmonizing using in-hwa, and (g) flexible and confident with managing paradox and complexity through zhung-yong.

These indigenous themes based on Confucianism support but also challenge the findings of past Korean management related research. For example, as the cross-cultural comparative studies (e.g., Hofstede et al., 2010; House et al., 2004) concluded, our findings suggested that Korean employees (albeit within private companies) prefer managers who build interpersonal relationships. However, our study found that Korean employees also prefer a participative management style, and regard authoritarian managers as ineffective which challenges the findings of the Stage 2 (etic-to-emic) studies. In this sense, our findings provide a warning against the application of cultural stereotypes to determine effective managerial practices without an understanding the indigenous cultural contexts.

Our emergent overarching indigenous themes of Korean managerial behavior based on Confucianism lend some support to the findings of other Stage 3 (emic-as-emic) indigenous studies of Korean management. For example, the indigenous themes were similar in meaning to 
the leadership competencies developed by Choi et al. (2012). However, these researchers did not capture the indigenous contexts where those competencies were exercised and applied. Moreover, it is noteworthy that our findings are based on the perceptions of managers as well as nonmanagerial employees who possess actual experiences interacting with leaders, whereas Choi et al.’s (2012) findings were solely derived from opinions of 15 leadership development practitioners. Our findings are also similar to those resulting from Wang's (2011) indigenous Chinese study of managerial effectiveness, but there are significant differences which stem from different interpretations of Confucianism (Kim et al., 2013). Effective managers in both national cultures maintain and develop interpersonal relationships. However, Chinese guanxi refers to the tendency to treat others differently based on the relationships with the others, whereas Korean in$h w a$ requires employees to be loyal to managers and employers in an organizational context (Kim et al., 2013). Therefore, our findings support the notion argued by Lin and Ho (2009) that some Confucian values and interpretations could be different across countries because each country emphasizes different parts of the Confucian values and principles based on national history, culture, and cultural transformation.

The indigenous themes of our study are also compatible with the paternalistic leadership style from Stage 4 (emic-and-etic) indigenous studies. For example, the themes are almost identical to the described dimensions of benevolence and moral character in Cheng et al.'s (2014) Global Paternalistic Leadership construct and scale, but not in the dimension of authoritarianism. In our study, participants preferred managers who treat their followers as a father is expected to do. Confucianism and Korean organizational culture of chae-bol may significantly impact the perceptions of Korean managers and non-managerial employees regarding what behaviorally distinguishes effective managers from ineffective managers. 
Our findings revealed that the doctrine of zhung-yong, one of the core tenets of Confucianism, is significantly embedded in the overall indigenous themes. In particular, the last theme, being flexible and confident with managing paradox and complexity, explicitly identifies the influence of zhung-yong on perceptions of effective leadership prototypes. For example, even though the participants expected their managers to assign tasks fairly (being fair), to provide feedback (being supportive), and to empower their team members (being long-term oriented), they also emphasized that their managers should be flexible according a given situation, such as assigning different types and levels of tasks, providing feedback according to subordinates' characteristics, and delegating tailored responsibilities. Another critical example is that although in our study managers who pursue harmony were perceived as effective, they were perceived as ineffective if they excessively emphasized harmony.

More importantly, the participants indicated that managers in Korea should be confident with managing paradox and complexity to deal with the current dynamic business environment where the global economy, business trends, technology, and customer preferences are constantly changing. In particular, they should embrace a mix of opposite but complementary national and corporate cultures. For example, the traditional authoritarian, hierarchical, and harmonious Korean cultural norms, where job security was exchanged for loyalty and trust (Chang, 2012), have been challenged since the financial crisis of 1997. Individual performance has become important criteria for appraisals and promotions, and organizational structures have become more flat due to fewer position levels and decision-making processes and increased empowerment (Chang, 2012). This cultural shift was revealed by our study participants' preference for individualism. 
Several scholars have highlighted the significance of this type of flexible leadership (see Smith, Besharov, Wessels, \& Chertok, 2012; Yang \& Kelly, 2009). Rather than emphasizing either one or the other, flexible leaders emphasize both delegation and direction, both prompt tasks and long-term vision, and both performance and employee development (Yang \& Kelly, 2009). By implementing zhung-yong and replacing their either/or with both/and thinking, managers in Korea can better manage the paradox and complexity. In this sense, the current study is significant and unique as we discovered the presence of the concept of zhung-yong in shaping employees' perceptions of managerial and leadership effectiveness.

Our findings confirm ILT because, as demonstrated, Korean cultural concepts are significantly embedded in the emergent indigenous themes of Korean managerial behaviors. The themes reflect the implicit cognitive prototypes held by Korean managers and non-managerial employees, which become criteria to distinguish effective from ineffective managerial behaviors. Possible reasons for differences with prior management studies in Korea

Several similarities and differences have been identified between our study and the previously discussed Korean management studies. The possible reasons for the differences could relate to different (a) perspectives, (b) research methodologies and methods, and (c) transformation of organizational and national cultures. First, the same phenomena could be interpreted differently depending on the philosophical perspectives and cultural backgrounds of the researchers. For example, Hofstede et al.'s (2010) sole dimension of individualism and collectivism could be interpreted differently in Triandis's (1995) two-dimension model. Triandis introduced two types of individualism and collectivism, including vertical and horizontal from the combination of "the four kinds of self: independent or interdependent (Markus \& Kitayama, 1991) and same or different" (Triandis, 1995: 44). The vertical dimension accepts inequality 
whereas the horizontal dimension emphasizes similarity in people's attributes, especially status. Hofstede's dimension is matched with horizontal individualism and vertical collectivism (Triandis, 1995), whereas individualistic behaviors in Korea belong to vertical individualism because Korean employees behave individualistically while still accepting inequality. Consequently, Hofstede's individualism may differ from individualism in a Korean context, which may lead to incomplete interpretations of Korean culture.

Second, different methodologies and methods can result in different findings. While exploitative approaches allow for identities of required competencies based on frequencies of observed behaviors, our exploratory qualitative approach embraced specific contexts in the Korean national and corporate culture ( $\mathrm{Li}, 2012)$. Different characteristics of research participants may be another reason for the differences. We focused on collecting our empirical data from managers at all levels and non-managerial employees, and we balanced the demographics. In sharp contrast, House et al. (2004) focused on the strategic leadership of general managers and selected only middle managers for their sample of research respondents; and Choi et al. (2012) obtained their data from leadership development practitioners.

Last, Leung et al. (2005) claimed that culture, as dynamic and transformable, plays a significant role in the different findings of managerial effectiveness. Korean employees preserve their inherited cultural values while they are also influenced by new cultural values from other countries, which could transform the notions and thus the perceptions of effective and ineffective managers. As previously explained, Korea is experiencing a cultural mixture of opposite but complementary national and corporate cultures due to the influx of Western culture. In our study, there is evidence in the behavioral underpinning of the negative BCs that our participants prefer participative rather than authoritarian managers. Although both participative and authoritarian 
management styles have long been evident within Korean organizational contexts, participative management styles appear to have been promoted more by Western cultural values.

\section{Implications for practice}

Our findings offer several broad implications for HR professionals, managers, and expatriates who manage Korean employees. First, MNCs and Korean private organizations could develop a list of key performance indicators based on the overarching indigenous themes of effective and ineffective managerial behaviors. The key performance indicators could be used to measure the behavioral effectiveness of managers in the Korean cultural context. Korean managers in Korean private companies and expatriate managers of MNCs in Korea can also incorporate these behavioral criteria to become more successful managers.

Second, Korean organizations and foreign MNCs in Korea could become better prepared to leverage opportunities and challenges in the global environment by using our findings to help them recruit, assess, and develop both their Korean and expatriate managers. HR professionals could play a critical role in developing an indigenous management competency model, which could be further developed to create assessment tools for recruiting managers and measuring the perceived behavioral effectiveness of the recruited managers. Although the indigenous themes and BCs of Korean managerial behaviors resulting from our study have not been generalized beyond the population of managers studied, we suggest that they could indicate an emerging picture of implicit cognitive prototypes about what an effective or ineffective manager looks like in a Korean private organization.

Third, in our study themes related to paternalistic (Cheng et al., 2014) and flexible styles of managing and leading (Yang \& Kelly, 2009) based on Confucianism in Korea emerged and were significantly valued by our research participants. Hence, as Li (2012) and Liden and 
Antonakis (2009) argued, by adopting managerial and leadership styles based on indigenous theories and philosophies that are in fit with the implicit leadership prototype expectations of those people around them, managers are better able to manage and lead their teams effectively.

Finally, our findings attest to how the implicit cognitive prototypes about managerial and leadership effectiveness held by Korean employees are influenced by Korean cultural concepts. Thus, insights based on Confucianism might help indigenous as well as expatriate managers in a Korean context become more effective managers. In particular, our findings could assist them and also non-Korean HR professionals of global MNCs in Korea in gaining a better understanding of Korean organizational culture and the culturally embedded effective/ineffective managerial and leadership behaviors. For MNCs, this could lead to greater success in managing/leading their indigenous managers and employees.

\section{Limitations of the study and directions for future research}

We acknowledge several limitations of our study. First, as an exploratory qualitative study with a small sample of 45 managers and non-managerial employees, the findings of our study have limited generalizability. In future research, larger samples of participants should be included for generalization. More managerial and leadership effectiveness studies drawing on data from similar samples of private companies in various industries could help identify additional BSs/BCs. Second, our findings might not be applicable to public and non-profit organizations in a Korean context. According to Schraeder, Tears, and Jordan (2005), public organizations are more stable, conservative, and hierarchical, so they may have a different organizational culture from private organizations. Multiple replication studies are recommended to identify additional BSs/BCs from future managerial and leadership effectiveness studies in different organizational sectors. Furthermore, a multiple cross-case/cross-sector comparative 
study using the findings of these studies and our study as the empirical source data needs to be conducted to explore whether the behavioral indicators of perceived managerial and leadership effectiveness are similar or different among the various types of organizations. Third, as we did not analyze the demographic data of the participants in our study, the impact of the demographic variables is unknown. Once similar studies with larger samples of participants are conducted, more generalizable subgroup analysis could be conducted. Last, consideration could also be given to exploring the extent to which our findings are global (context-general) or local (contextspecific). This could be achieved by conducting a Stage 4 (emic and etic) cross-indigenization geocentric comparative analysis using findings from equivalent Stage 3 (emic-as-emic) replication managerial behavior studies already carried out in other countries.

\section{Conclusion}

As the first indigenous emic study of perceived managerial and leadership effectiveness conducted in Korea from a Stage 3 (emic-as-emic) perspective, our research could become a cornerstone for more advanced indigenous empirical studies on this topic in Korea. It is our hope that our emic research findings could become a catalyst for dialogue related to indigenous management/leadership research, especially in the Korean context and other East Asian contexts. 


\section{References}

Alvesson, M., \& Sveningsson, S. 2003. The great disappearing act: Difficulties in doing "leadership". The Leadership Quarterly, 14: 359-381.

Amabile, T. M., Schatzel, E. A., Moneta, B., \& Kramer. S. J. 2004. Leader behaviors and work environment for creativity: Perceived leader support. The Leadership Quarterly, 15: 5-32.

Ames, R. T., \& Rosemont, Jr., H. 1998. The analects of Confucius: A philosophical translation. Toronto, Canada: The Random House, Inc.

Borman, W. C., \& Brush, D. H. 1993. More progress toward a taxonomy of managerial performance requirements. Human Performance, 6(1): 1-21.

Braun, V., \& Clarke, V. 2006. Using thematic analysis in psychology. Qualitative Research in Psychology, 3: 77-101.

Cammock, P., Nilakant, V., \& Dakin, S. 1995. Developing a lay model of managerial effectiveness: A social constructionist perspective. Journal of Management Studies, 32: 443-474.

Chang, H., \& Holt, R. 1994. A Chinese perspective on face as inter-relational concern. In S. T. Toomey (Ed.), The challenge of face work: 95-132. Albany, NY: State University of New York Press.

Chang, S. 2012. Study on human resource management in Korea's chaebol enterprise: A case study of Samsung Electronics. International Journal of Human Resource Management, 237: 1536-1561.

Chell, E. 2004. Critical incident technique. In C. Cassell \& G. Symon (Eds.), Essential guide to qualitative methods in organizational research (pp. 45-69). London: Sage. 
Chen, G.-M., \& Chung, J. 1994. The impact of Confucianism on organizational communication. Communication Quarterly, 42(2): 93-105.

Cheng, B. S. 1995. Paternalistic authority and leadership: A case study of a Taiwanese CEO. Bulletin of the Institute of Ethnology Academic Sinica, 79: 119-173 (in Chinese).

Cheng, B. S. 1996. Authoritarian-orientation value and paternalistic leadership: The concept and its measurement. Report prepared for Taiwan's National Science Council. Taiwan, National Taiwan University (in Chinese).

Cheng, B., Boer, D., Chou, L., Huang, M., Yoneyama, S., Shim, D., ... Tsai, C. 2014. Paternalistic leadership in four East Asian societies: Generalizability and cultural differences of the Triad model. Journal of Cross-Cultural Psychology, 45: 82-90.

Cho, Y., \& Yoon, J. 2001. The origin and function of dynamic collectivism: An analysis of Korean corporate culture. Asia Pacific Business Review, 7(4): 70-88.

Choe, S. 2006. Wal-Mart selling stores and leaving South Korea, New York Times, http://www.nytimes.com/2006/05/23/business/worldbusiness/23shop.html?_r=0. Accessed June 20, 2014.

Choi, J., \& Patterson, D. 2007. Conglomerate regulation and aggregate concentration in Korea: An empirical analysis. Journal of the Asia Pacific Economy, 122: 250-271.

Choi, M., Yoon, H. J., \& Jeung, C. 2012. Leadership development in Korea: A Delphi study. Asia Pacific Journal of Human Resources, 50: 23-42.

Chuang, S. 2012. Confucianization through globalization: Evidence from the US. Journal of Chinese Human Resource Management, 3(2): 118-135.

Clark, D. N. 2000. Culture and customs of Korea. Westport, CT: Greenwood. 
Cronshaw, S. F., \& Lord, R. G. 1987. Effect of categorization, attribution, and encoding processes on leadership perceptions. Journal of Applied Psychology, 72: 97-106.

Cunliffe, A. L. 2011. Crafting qualitative research: Morgan and Smircich 30 years on. Organizational Research Methods, 14: 647-673.

Eden, D., \& Leviatan, U. 1975. Implicit leadership theory as a determinant of the factor structure underlying supervisory behavior scales. Journal of Applied Psychology, 60: 736-741.

Farh, J. L., \& Cheng, B. S. 2000. A cultural analysis of paternalistic leadership in Chinese organizations. In J. T. Li., A. S. Tsui, \& E. Weldon (Eds.), Management and organizations in the Chinese context: 85-127. London: Macmillan.

Festing, M., \& Maletzky, M. 2011. Cross-cultural leadership adjustment: A multilevel framework based on the theory of structuration. Human Resource Management Review, 21: 186-200.

Flanagan, J. C. 1954. The critical incident technique. Psychological Bulletin, 51: 327-358.

Flick, U. 2002. An introduction to qualitative research (2nd ed.). London: Sage.

Foti, R. J., \& Luch, C. H. 1992. The influence of individual differences on the perception and categorization of leaders. The Leadership Quarterly, 3: 55-66.

Gardner, D. K. 2007. The four books: The teachings of the later Confucian tradition. Indianapolis, IN: Hackett Publishing.

Gerstner, C. R., \& Day, D. V. 1994. Cross-cultural comparison of leadership prototypes. The Leadership Quarterly, 5: 121-134.

Gibbs, G. 2007. Analyzing qualitative data: The Sage qualitative research kit. London: Sage. 
Granrose, C. 2001. The challenge of Confucius: The generalizability of North American career assumptions. In B. Kidd, X. Li, \& J. Richter (Eds.), Maximizing human intelligence deployment in Asia business: The sixth generation project: 96-123. New York: Palgrave.

Gremler, D. D. 2004. The critical incident technique in service research. Journal of Service Research, 7(1): 65-89.

Guba, E. G., \& Lincoln, Y. S. 1994. Competing paradigms in qualitative research. In N. K. Denzin \& Y. S. Lincoln (Eds.), Handbook of qualitative research: 105-117. London: Sage.

Hall, E. T. 1976. Beyond culture. Garden City, NY: Doubleday.

Hamlin, R. G. 1988. The criteria of managerial effectiveness within secondary schools. CORE: Collected Original Resources in Education, 12(1): 1-221.

Hamlin, R. G. \& Patel, T. 2012. Behavioural indicators of perceived managerial and leadership effectiveness in Romanian and British public sector hospitals. European Journal of Training and Development, 36(2/3): 234-261.

Harris, M. 1999. Theories of culture in postmodern times. Walnut Creek, CA: AltaMira Press.

Helgstrand, K. K., \& Stuhlmacher, A. F. 1999. National culture: An influence on leader evaluations. The International Journal of Organizational Analysis, 7(2): 153-168.

Hofstede, G., \& Bond, M. H. 1988. The Confucius connection: From cultural roots to economic growth. Organizational Dynamics, 16(4): 5-21.

Hofstede, G., Hofstede, G., \& Minkov, M. 2010. Cultures and organizations: Software of the mind (3rd ed.). New York, NY: McGraw-Hill.

Horak, S. 2014. Antecedents and characteristics of informal relation-based networks in Korea: Yongo, Yonjul and Inmaek. Asia Pacific Business Review, 20(1): 78-108. 
House, R.J., \& Aditya, R. N. 1997. The social scientific study of leadership: Quo vadis? Journal of Management, 23: 409-465.

House, R. J., Hanges, P. J., Javidan, M., Dorfman, P. W., \& Gupta, V. 2004. Culture, leadership and organizations: The GLOBE study of 62 societies. London: Sage.

Johns, G. 2006. The essential impact of context on organizational behavior. Academy of Management Review, 31: 386-408.

Kim, A. E., \& Park, G.-S. 2003. Nationalism, Confucianism, work ethic and industrialization in South Korea. Journal of Contemporary Asia, 33(1): 37-49.

Kim, S. 2002. Anti-Americanism in Korea. The Washington Quarterly, 26(1): 109-122.

Kim, T. G., Lee, J. K., \& Lee, J. H. 2013. Do interpersonal relationships still matter for turnover intention? A comparison of South Korea and China. The International Journal of Human Resource Management, 24: 966-984.

Kim, U. M. 1994. Significance of paternalism and communalism in the occupational welfare system of Korean firms: A national survey. In U. Kim, H. C. Triandis, C. Kagitcibasi, S. Choi, \& G. Yoon (Eds.), Individualism and collectivism: Theory, method, and applications: 251-266. London: Sage.

Knafl, K. A., \& Breitmayer, B. J. 1991. Triangulation in qualitative research: Issues of conceptual clarity and purpose. In J. M. Morse (Ed.), Qualitative nursing research: A contemporary dialogue: 226-239. London: Sage.

Knutson, T. J. 1996. Korean communication practices: The moon knows. Korean Fulbright Forum, 12: 1-20. 
Korea Fair Trade Commission (KFTC). 2012. Report for the lists of corporate groups which are restricted for mutual contribution/investment, http://www.ftc.go.kr/news/ftc/reportView.jsp?report_data_no=4722. Accessed June 20, 2014.

Kotterman, J. 2006. Leadership versus management: What's the difference? Journal for Quality \& Participation, 29(2): 13-17.

Latham, G. P., \& Wexley, K. N. 1981. Increasing productivity through performance appraisal. Reading, MA: Addison-Wesley.

Lee, C. Y. 2012. Korean culture and its influence on business practice in South Korea. Journal of International Management Studies, 7(2): 184-191.

Lee, H. 1998. Transformation of employment practices in Korean businesses. International Studies of Management and Organization, 28(4): 26-39.

Lee, H. 2006. Essential characteristics of policy balance in Confucian philosophy. Korean Journal of Policy Studies, 44(2): 1-24.

Lee, J. H. 2012. The imagination and creativity of Yin Yang. Korean Academy of Managed Care Pharmacy, 61: 461-485.

Lee, S. H. 2000. Argument of Asiatic value and the future of Confucian culture. In Korean identity in the new millennium (5Section): 12-27. Seoul, Korea: The Academy of Korean Studies.

Leung, K. 2007. The glory and tyranny of citation impact: An East Asian perspective. Academy of Management Review, 31: 386-408.

Leung, K., Bhagat, R. S., Buchan, N. R., Erez, M., \& Gibson, C. B. 2005. Culture and international business: Recent advances and their implications for future research. Journal of International Business Studies, 36: 357-378. 
Li, P. P. 2012. Toward an integrative framework of indigenous research: The geocentric implications of yin-yang balance. Asia Pacific Journal of Management, 29: 849-872.

Li, P. P., Zhou, K., \& Sekiguchi, T. 2014. Special issue on indigenous management research in Asia. Asia Pacific Journal of Management, http://www.springer.com/cda/content/document/cda_downloaddocument/APJM+SI+Call +for+Papers+New+Peter+Ping+Li.docx?SGWID=0-0-45-1440277-p35740616. Accessed June 28, 2014.

Liden, R. C., \& Antonakis, J. 2009. Considering context in psychological leadership research. Human Relations, 62: 1587-1605.

Lin, L., \& Ho, Y. 2009. Confucian dynamism, culture and ethical changes in Chinese societies- a comparative study of China, Taiwan, and Hong Kong. The International Journal of Human Resource Management, 20: 2402-2417.

Lyles, M. 2009. Call for proposal submission for Dissertation grant and workshop: International Association for Chinese Management Research, http://www.iacmr.org/Publications/MOR/IndigenousResearch/Definition\%20of\%20Indig Indig\%20Research\%20MOR.pdf. Accessed June 20, 2014.

Markus, H. R., \& Kitayama, S. 1991. Culture and the self: Implications for cognition, emotion, and motivation. Psychological Review, 98: 224-253.

Merkin, R. S. 2009. Cross-cultural communication patterns - Korean and American communication. Journal of Intercultural Communication, 20, http://www.immi.se/intercultural/nr20/merkin.htm. Accessed May 1, 2015.

Merriam, S. B. 2009. Qualitative research: A guide to design and implementation. San Francisco: Jossey-Bass. 
Middlehurst, R. 2008. Not enough science or not enough learning? Exploring the gap between leadership theory and practice. Higher Education Quarterly, 62: 322-339.

Morgan, D. L. 2007. Paradigms lost and pragmatism regained: Methodological implications of combining qualitative and quantitative methods. Journal of Mixed Methods Research, 1(1): 48-76.

Mumford, M. D. 2011. A hale farewell: The state of leadership research. The Leadership Quarterly, 22: 1-7.

Noordegraaf, M., \& Stewart, R. 2000. Managerial behavior research in private and public sectors: Distinctiveness, disputes, and directions. Journal of Management Studies, 37: 427-443.

Oh, H. S., Chung, M. H., \& Labianca, G. 2004. Group social capital and group effectiveness: The role of informal socializing ties. Academy of Management Journal, 47: 860-875.

Padilla, A., Hogan, R., \& Kaiser, R. B. 2007. The toxic triangle: Destructive leaders, susceptible followers, and conducive environments. The Leadership Quarterly, 18: 176-194.

Park, J. 2013. Three minutes Asian classics. Seoul, Korea: The Tiny Seed.

Patton, M. Q. 2002. Qualitative research and evaluation methods (3rd ed.). Thousand Oaks, CA: Sage.

Pellegrini, E. K., \& Scandura, T. A. 2006. Leader-member exchange (LMX), paternalism and delegation in the Turkish business culture: An empirical investigation. Journal of International Business Studies, 37: 264-279.

Pellegrini, E. K., Scandura, T. A., \& Jayaraman, V. 2010. Cross-cultural generalizability of paternalistic leadership: An expansion of leader-member exchange theory. Group \& Organization Management, 35: 391-420. 
Phillips, J. S., \& Lord, R. G. 1986. Notes on the practical and theoretical consequences of implicit leadership theories for the future of leadership measurement. Journal of Management, 12(1): 31-42.

Ponterotto, J. 2005. Qualitative research in counseling psychology: A primer on research paradigms and philosophy of science. Journal of Counseling Psychology, 52(2): 126-136.

Pratt, K. I. 2006. Everlasting flower: A history of Korea. London: Biddles Ltd.

Puck, J. F., Kittler, M. G., \& Wright, C. 2008. Does it really work? Re-assessing the impact of pre-departure cross-cultural training on expatriate adjustment. International Journal of Human Resource Management, 19: 2182-2197.

Raelin, J. 2004. Don't bother putting leadership into people, Academy of Management Executive, 18: $340-355$.

Robinson, J. H. 1996. Professional communication in Korea: Playing things by eye. IEEE Transactions on Professional Communication, 39(3): 129-134.

Ruiz, C. E., Wang, J., \& Hamlin, R. G. 2013. What makes managers effective in Mexico? Leadership \& Organization Development Journal, 34(2): 130-146.

Schraeder, M., Tears, R., \& Jordan, M. 2005. Organizational culture in public sector organizations: Promoting change through training and leading by example. Leadership \& Organization Development Journal, 26: 492-502.

Shaw, J. B. 1990. A cognitive categorization model for the study of intercultural management, Academy of Management Review, 10: 435-54.

Shim, T., Y., Kim, M. S., \& Martin, J. N. 2008. Changing Korea: Understanding culture and communication. New York: Peter Lang. 
Shipper, F., \& Davy, J. 2002. A model and investigation of managerial skills, employees' attitudes, and managerial performance. The Leadership Quarterly, 13: 95-120.

Shondrick, S. J., \& Lord, R. G. 2010. Implicit leadership and followership theories: Dynamic structures for leadership perceptions, memory, and leader-follower processes. In G. P. Hodgkinson \& J. K. Ford (Eds.), International Review of Industrial and Organizational Psychology: vol 25, 1-33. Chichester, UK: John Wiley \& Sons.

Shondrick, S. J., Dinh, J. E., \& Lord, R. G. 2010. Developments in implicit leadership theory and cognitive science: Applications to improving measurement and understanding alternatives to hierarchical leadership. The Leadership Quarterly, 21: 959-978.

Siddique, C. M. 2004. Job analysis: A strategic human resource management practice. International Journal of Human Resource Management, 15: 219-244.

Smith, W. K., Besharov, M. L., Wessels, A. K., \& Chertok, M. 2012. A paradoxical leadership model for social entrepreneurs: Challenges, leadership skills, and pedagogical tools for managing social and commercial demands. Academy of Management Learning \& Education, 11: 463-478.

Stewart, G. L., \& Nandkeolyar, A. K. 2007. Exploring how constraints created by other people influence intra-individual variation in objective performance measures. Journal of Applied Psychology, 92: 1149-1158.

Su, Y. 2011. Lifelong learning as being: The Heideggerian perspective. Adult Education Quarterly, 61(1): 57-72.

Tang, T. 2012. A Chinese theory of scholarly inquiry: Inspirations for making unique and interesting contributions. Journal of Chinese Human Resource Management, 3(1): 4-15.

Triandis, H. C. 1995. Individualism and collectivism. Boulder, CO: Westview Press. 
Tsui, A. S. 1990. A multiple-constituency model of effectiveness: An empirical examination at the human resource subunit level. Administrative Science Quarterly, 35: 458-483.

Tsui, A. S. 2004. Contributing to global management knowledge: A case for high quality indigenous research. Asia Pacific Journal of Management, 21: 491-513.

Tsui, A. S. 2006. Contextualization in Chinese management research. Management and Organization Review, 2: 1-13.

Tsui, A. S. 2007. From homogenization to pluralism: International management research in the Academy and beyond. Academy of Management Journal, 50: 1353-1364.

Wang, J. 2011. Understanding managerial effectiveness: A Chinese perspective. Journal of European Industrial Training, 35(1): 6-23.

Weber, R. P. 1990. Basic content analysis (2nd ed.). Thousand Oaks, CA: Sage.

Willis, J. W. 2007. Foundations in qualitative research: Interpretive and critical approaches. Thousand Oaks, CA: Sage.

Wolfgramm, R., Spiller, C., \& Voyageur, C. 2014. Special issue leadership journal: Indigenous leadership. Leadership, 10: 263-265.

Woo, J. 2013. Did cranky consumers force Yahoo out of Korea? The Wall Street Journal, http://blogs.wsj.com/korearealtime/2013/01/04/did-cranky-consumers-force-yahoo-outof-korea/. Accessed June 20, 2014.

Yang, I., \& Kelly, A. 2009. Assumptions in Korean organizations and their implications in a cross-cultural setting. Advances in Global Leadership, 5: 297-320.

Yielder, J. \& Codling, A. 2004. Management and leadership in the contemporary university. Journal of Higher Education Policy and Management, 36: 315-328.

Yin, R. K. 2010. Qualitative research from start to finish. New York: The Guilford Press. 
Yukl, G., Gordon, A., \& Taber, T. 2002. A hierarchical taxonomy of leadership behavior:

Integrating a half century of behavior research. Journal of Leadership and Organizational Studies, 9(1): 15-31. 